\title{
Produção de forragem e desempenho de novilhos de corte em um sistema silvipastoril: efeito de doses de nitrogênio e oferta de forragem ${ }^{1}$
}

\author{
Fernando Salgado Bernardino², Rafael Gonçalves Tonucci², Rasmo Garcia², Júlio César \\ Lima Neves ${ }^{3}$, Gabriel Cipriano Rocha ${ }^{2}$
}

\footnotetext{
1 Projeto parcialmente financiado pela FAPEMIG

2 Departamento de Zootecnia - Universidade Federal de Viçosa.

${ }^{3}$ Departamento de Solos - Universidade Federal de Viçosa
}

RESUMO - O estudo foi realizado com o objetivo de avaliar a produção forrageira e o desempenho de bovinos de corte pastejando sub-bosque de um sistema silvipastoril com eucalipto, adubado com fertilizante nitrogenado e duas ofertas de forragem. Os tratamentos consistiram de três doses de fertilizante nitrogenado (0, 75 e $150 \mathrm{~kg} \mathrm{ha}^{-1}$ de $\mathrm{N}$, na forma de ureia), e duas ofertas de forragem (10 e 15\% PV). O estudo foi conduzido sob delineamento inteiramente casualizado, com quatro repetições e três períodos de avaliação. Foi observado aumento no ganho de peso, apenas no primeiro período de avaliação, à medida que se elevaram as doses de fertilizante nitrogenado. A variação na oferta de forragem não influenciou os ganhos médios individuais. O ganho por unidade de área aumentou à medida que foram adicionadas doses crescentes de fertilizante nitrogenado. A oferta de forragem de 15\% é mais adequada quando se utilizam menores doses de nitrogênio na pastagem. Para doses mais elevadas, a intensificação da utilização resulta em maiores ganhos por unidade de área. A fertilização do sub-bosque é eficiente e necessária para a intensificação do uso de sistemas integrados eucalipto-pastagem.

Palavras-chave: agrossilvipastoril, fertilização, sombreamento

\section{Forage yield and performance of beef steers in a silvopastoral system: effects of forage offers and nitrogen fertilization}

\begin{abstract}
The objective of this study was to evaluate forage yield and performance of beef cattle grazing understory of a silvopastoral system with eucalyptus, fertilized with nitrogen and two forage offers. Treatments consisted of three doses

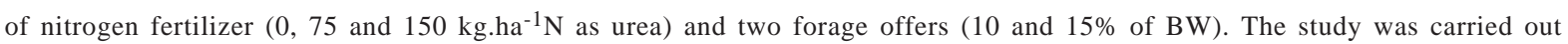
in a complete randomized design with four replications and three evaluation periods. It was observed an increment in weight gain only the first period of evaluation as doses of nitrogen fertilizer were increased. Variation on forage offer did not influence individual average gains. Values of gain per area unit increased as increasing doses of nitrogen fertilizer were added. Forage offer of $15 \%$ is more properly when lower doses of $\mathrm{N}$ were used in pastures. For higher doses, intensification of use results in greater gains per area unit. Understory fertilization is efficient and necessary for intensification of the use of eucalyptuspasture integrated systems.
\end{abstract}

Key Words: agrosilvopastoral, fertilization, shading

\section{Introdução}

Os sistemas silvipastoris, modalidade dos sistemas agroflorestais, referem-se às técnicas de produção nas quais se integram animais, plantas forrageiras e árvores na mesma área. Esses sistemas representam uma forma de uso da terra, em que as atividades silviculturais e pecuárias são combinadas para gerar produção de forma complementar pela interação dos seus componentes (Garcia \& Couto, 1997).

Segundo Payne (1985), a máxima produtividade dos sistemas silvipastoris é obtida quando a máxima quantidade de produto animal é obtida sem que ocorra decréscimo na produção da cultura arbórea, e vice-versa. Por isso, a produtividade desses sistemas deve ser medida somente com base no produto comercializado da unidade de área (Nair, 1993).

Em um sistema silvipastoril, além de aumentar a produção animal, cuidados devem ser tomados para não haver prejuízo ao componente arbóreo. A perenidade e estabilidade do sistema dependem de práticas de manejo diversas, entre elas, a reposição de nutrientes via fertilização e a adoção de oferta de forragem compatível com a capacidade de suporte da pastagem. Segundo Gomide \& Gomide (2001), taxas de lotação muito acima ou muito abaixo 
da capacidade de suporte resultam em subestimativas do desempenho animal e da produção animal por área.

Segundo Gomide et al. (2001), a pressão de pastejo é uma estratégia importante no manejo da pastagem, uma vez que, diferentemente da taxa de lotação, considera a disponibilidade momentânea de matéria seca, portanto reflete melhor a estreita relação entre animal e planta, além de propiciar equilíbrio entre a produção desses fatores.

Por outro lado, a fertilização da pastagem tem como resultados aumento da produção de matéria seca e melhoria da qualidade nutricional da forragem, aumentando diretamente a capacidade de suporte do sistema, permitindo o uso de maiores taxas de lotação.

Este trabalho foi conduzido com o objetivo de verificar a influência da adubação nitrogenada e de duas ofertas de forragem no desempenho animal de bovinos pastejando o sub-bosque de um sistema silvipastoril com eucalipto.

\section{Material e Métodos}

O estudo foi conduzido na Fazenda Riacho, pertecente ao grupo Votarantim- Siderurgia, localizada no município de Vazante-MG. A fazenda está localizada no bioma Cerrado e possui como características climáticas: precipitação média anual de $1.350 \mathrm{~mm}$ (concentrada no período de outubro a abril), temperatura média anual de $22,0^{\circ} \mathrm{C}$, umidade relativa do ar em torno de $72,5 \%$, e altitude de $650 \mathrm{~m}$. Os dados meteorológicos do período experimental foram colhidos em estação meteorológica localizada na fazenda onde o trabalho foi realizado (Tabela 1).

O experimento foi instalado em um sistema agrossilvipastoril implantado em novembro de 1999 com um clone de Eucalyptus camaldulensis plantado com espaçamento de $10 \mathrm{~m}$ entre linhas e $4 \mathrm{~m}$ entre árvores. As árvores apresentavam diâmetro médio à altura do peito
(DAP) de 25,0 cm e altura média de $26 \mathrm{~m}$. As linhas de plantio foram orientadas no sentido leste-oeste.

Junto com o plantio do eucalipto, em 1999, foi realizado o cultivo de arroz de sequeiro nas entrelinhas. Na ocasião, foram aplicados $4,5 \mathrm{tha}^{-1}$ de calcário dolomítico, $\mathrm{PRNT}=85 \%$, e 100 g por cova da fórmula NPK 10-28-6. Para o arroz, foram utilizados $300 \mathrm{~kg} \mathrm{ha}^{-1}$ da fórmula NPK 4-30-16. No ano seguinte, cultivou-se soja na área, variedade Conquista, com a utilização de $300 \mathrm{~kg} \mathrm{ha}^{-1}$ da fórmula NPK 2-30-15. Em 2001, procedeu-se à semeadura a lanço da gramínea (Brachiaria brizantha cv. Marandu), utilizando-se $4,8 \mathrm{~kg} \mathrm{ha}^{-1}$ de sementes puras viáveis. Na ocasião, foram aplicados $150 \mathrm{~kg} \mathrm{ha}^{-1}$ de fosfato reativo e $150 \mathrm{~kg} \mathrm{ha}^{-1} \mathrm{de}$ superfosfato simples, conforme recomendações baseadas na análise de solo. A gramínea apresentou bom estabelecimento, sendo o sistema então utilizado para recria de novilhos sob pastejo em lotação contínua.

Foram utilizados seis piquetes de 4,5 ha, delimitados com cercas eletrificadas. Em cada piquete, foi aplicado, aleatoriamente, um dos seis tratamentos, constituídos de três níveis de fertilização nitrogenada $\left(0,75\right.$ e $150 \mathrm{~kg} \mathrm{ha}^{-1} \mathrm{de}$ $\mathrm{N}$ ), na forma de ureia, e duas ofertas de forragem (10 e 15\% do peso vivo animal). Os tratamentos foram dispostos em delineamento inteiramente ao acaso, arranjados no esquema de parcelas subdivididas com o fatorial $3 \times 2$ (níveis de nitrogênio $\times$ ofertas de forragem) constituindo as parcelas e três épocas de avaliação constituindo as subparcelas. Um piquete adicional, vizinho à área experimental, foi utilizado para manutenção dos animais reguladores, quando não estavam sendo utilizados no experimento. Para o fornecimento de água aos animais, foram instalados bebedouros, com distribuição de água por gravidade, abastecidos por um reservatório central. Na outra extremidade de cada piquete, foram colocados cochos de madeira para fornecimento de sal mineral aos animais, à vontade.

Tabela 1 - Temperaturas médias máximas e mínimas, precipitação acumulada e umidade relativa do ar, obtidas durante o período experimental

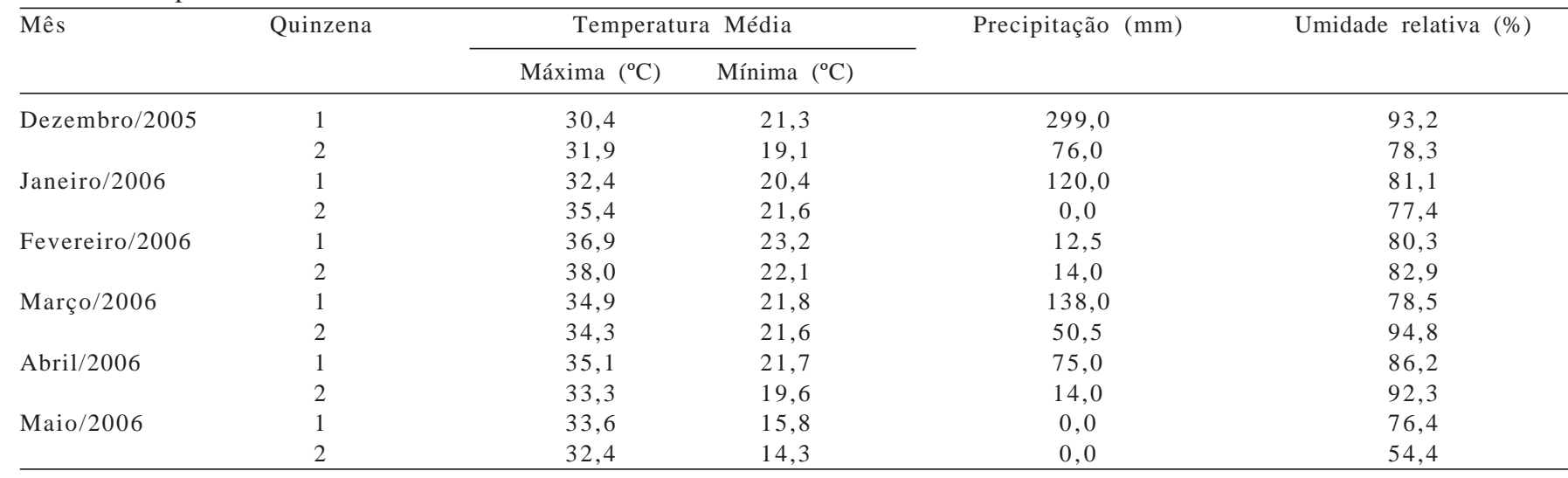


Foram utilizados novilhos da raça Nelore, com idade média de um ano e peso médio inicial de 183,5 kg, pertencentes ao rebanho da Fazenda Riacho. Os animais foram vacinados contra febre aftosa e carbúnculo sintomático, de acordo com calendário sanitário da região, e receberam vermífugos de amplo espectro no início do experimento.

O método de pastejo utilizado foi o de lotação contínua, com carga variável, conforme a técnica put and take (Mott \& Lucas, 1952). Quatro animais-teste foram empregados por piquete e número variável de animais reguladores foram colocados ou retirados dos piquetes com a finalidade de manter os níveis de oferta de forragem ajustados conforme os tratamentos propostos e de acordo com a taxa de crescimento do sub-bosque.

Na segunda quinzena de novembro de 2005 , foi realizado o rebaixamento do pasto, atingindo altura média de $10 \mathrm{~cm}$. Foi realizada amostragem do solo para análise prévia à aplicação dos tratamentos (Tabela 2).

A fertilização foi feita a lanço, na primeira semana do mês de dezembro, assim que as condições climáticas foram favoráveis. Além dos tratamentos, em todos os piquetes foram aplicados $80 \mathrm{~kg} \mathrm{ha}^{-1}$ de $\mathrm{P}_{2} \mathrm{O}_{5}$, a lanço em cobertura, na forma de superfosfato triplo.

Tabela 2 - Resultado da análise do solo antes da aplicação os tratamentos

\begin{tabular}{|c|c|}
\hline Variável & Valor \\
\hline pH água & 5,4 \\
\hline Matéria orgânica $\left(\right.$ dag $\mathrm{kg}^{-1}$ ) & 2,3 \\
\hline Fósforo $\left(\mathrm{mg} \mathrm{dm}^{-3}\right)$ & 1,7 \\
\hline Potássio (mg dm ${ }^{-3}$ ) & 37 \\
\hline Enxofre $\left(\mathrm{mg} \mathrm{dm}^{-3}\right)$ & 15,8 \\
\hline $\mathrm{Ca}^{2+}\left(\mathrm{cmol}_{\mathrm{c}} \mathrm{dm}^{-3}\right)$ & 1,1 \\
\hline $\mathrm{Mg}^{2+}\left(\mathrm{cmol}_{\mathrm{c}} \mathrm{dm}^{-3}\right)$ & 1,2 \\
\hline $\mathrm{Al}^{3+}\left(\mathrm{cmol}_{\mathrm{C}} \mathrm{dm}^{-3}\right)$ & 0,3 \\
\hline $\mathrm{H}+\mathrm{Al}\left(\mathrm{cmol}_{\mathrm{C}} \mathrm{dm}^{-3}\right)$ & 4,7 \\
\hline CTCt $\left(\mathrm{cmol}_{\mathrm{C}} \mathrm{dm}^{-3}\right)$ & 7,1 \\
\hline V (\%) & 33 \\
\hline m (\%) & 10 \\
\hline Areia (\%) & 14 \\
\hline Silte (\%) & 16 \\
\hline Argila (\%) & 70 \\
\hline Classe textural & Argila pesada \\
\hline
\end{tabular}

O experimento teve início 56 dias após a aplicação dos fertilizantes, quando os animais foram colocados na área. Antes do início do experimento e a cada intervalo de quatro semanas, todos os animais foram pesados em jejum de 12 horas. A distribuição nos piquetes foi realizada com a formação de grupos equilibrados a partir do seu peso vivo e estado corporal.

O pastejo foi realizado em três períodos subseqüentes de 30 dias. A cada período foi realizado o ajuste da carga animal à oferta de forragem estipulada com a entrada e saída de animais reguladores (Tabela 3 ).

A fertilização foi feita a lanço, na primeira semana do mês de dezembro, assim que as condições climáticas foram favoráveis. Além dos tratamentos, em todos os piquetes foram aplicados $80 \mathrm{~kg} \mathrm{ha}^{-1} \mathrm{de}_{2} \mathrm{O}_{5}$, a lanço em cobertura, na forma de superfosfato triplo.

O experimento teve início 56 dias após a aplicação dos fertilizantes, quando os animais foram colocados na área. Antes do início do experimento e a cada intervalo de quatro semanas, todos os animais foram pesados em jejum de 12 horas. A distribuição nos piquetes foi realizada com a formação de grupos equilibrados a partir do seu peso vivo e estado corporal.

O pastejo foi realizado em três períodos subseqüentes de 30 dias. A cada período foi realizado o ajuste da carga animal à oferta de forragem estipulada com a entrada e saída de animais reguladores (Tabela 3 ).

A estimativa da disponibilidade de matéria seca, presente instantaneamente no sub-bosque do sistema, foi feita a cada quatro semanas de intervalo, por meio do corte e da pesagem de amostras. A amostragem foi realizada em quadrados de 0,8 × 0,8 m. Foram retiradas 16 amostras de cada piquete, cortadas a cerca de $10 \mathrm{~cm}$ de altura em relação ao nível do solo. As amostras foram pesadas e armazenadas para posteriores análises laboratoriais.

Depois de cortado, o material foi pesado e congelado em freezer para ser transportado ao Laboratório de Nutrição Animal do Departamento de Zootecnia da UFV. As amostras foram secas em estufa a $65^{\circ} \mathrm{C}$, por 72 horas, moídas com peneira de $1 \mathrm{~mm}$ e submetidas às seguintes

Tabela 3 - Oferta de forragem pretendida e oferta de forragem real nos períodos de pastejo

\begin{tabular}{|c|c|c|c|c|}
\hline \multirow[t]{2}{*}{ Oferta pretendida (\% PV) } & \multirow[t]{2}{*}{ Nitrogênio (kg/ha) } & \multicolumn{3}{|c|}{ Oferta observada (\%PV) } \\
\hline & & Período 1 & Período 2 & Período 3 \\
\hline 10 & 0 & 12,2 & 12,6 & 12,8 \\
\hline 10 & 75 & 12,3 & 12,2 & 11,3 \\
\hline 10 & 150 & 13,4 & 11,6 & 10,2 \\
\hline 15 & 0 & 16,4 & 17,3 & 15,3 \\
\hline 15 & 75 & 16,9 & 17,7 & 14,9 \\
\hline 15 & 150 & 16,3 & 16,4 & 16,4 \\
\hline
\end{tabular}


análises: MS, por secagem a $105^{\circ} \mathrm{C}$; nitrogênio, pelo método semimicro Kjeldahl; potássio (fotometria de chama); fósforo (colorimetria); cálcio (absorção atômica), após digestão nítrico-perclórica (Silva \& Queiroz, 2002). Os teores de fibra em detergente neutro (FDN) foram analisados segundo o método ANCON ${ }^{\circledR}$, com modificações. As amostras foram colocadas em sacos de TNT (tecido não tecido), gramatura 100 , com tara conhecida e dimensão de $5 \times 5 \mathrm{~cm}$, que, depois de selados, foram levados a autoclave dentro de potes coletores universais por um período de 1 hora. Posteriormente, os sacos foram lavados em água destilada até que todo o detergente fosse retirado e, em seguida, foram levados para estufa de ventilação forçada a $65^{\circ} \mathrm{C}$ por 24 horas. Após essa etapa, os sacos foram levados para a estufa a $105^{\circ} \mathrm{C}$ por 4 horas. Os teores de FDN foram obtidos pela diferença entre o peso dos sacos antes e depois do tratamento com o detergente. O resíduo obtido foi utilizado para análise de nitrogênio insolúvel em detergente neutro (NIDN), segundo Licitra et al. (1996).

O ganho de peso médio diário dos animais-teste foi obtido pela diferença entre as pesagens realizadas no início e ao final de cada período de pastejo, dividido pelo número de dias em que os animais permaneceram pastejando.

Determinou-se o ganho de peso por hectare (G/ha) multiplicando o ganho médio diário dos animais teste pelo número de dias-novilho/ha, que, por sua vez, foi calculado pela contagem do número total de animais mantidos no piquete, em cada dia, multiplicado pelo número de dias de avaliação em cada período.

Os dados foram interpretados estatisticamente por meio de análise de variância e regressão. As doses de nitrogênio e ofertas de forragem foram arranjadas em esquema de parcelas subdivididas no tempo, portanto, com restrições à casualização do fator época. Os graus de liberdade referentes ao nitrogênio foram desdobrados em efeito linear e efeito quadrático. As anovas foram realizadas no programa Statistica for Windows 6, procedimento General Linear Models, e os desdobramentos pelo programa SAEG 5.0. Os valores dos quadrados médios do resíduo combinados foram obtidos pelo uso da fórmula de Satterwaite. Os modelos foram escolhidos com base na significância dos coeficientes de regressão, adotando-se o nível de 10\% de probabilidade, utilizando-se o teste "t" de Student.

\section{Resultados e Discussão}

A disponibilidade de MS do sub-bosque foi influenciada $(\mathrm{P}<0,01)$ pelas doses de fertilizante adicionadas. Para a oferta de $10 \%$, foi observado efeito linear nos períodos 1 e 3, e quadrático no segundo período. Para a oferta de 15\% verificaram-se efeito quadrático no primeiro período avaliado, e comportamento linear nos períodos subsequentes (Tabela 4).

A fertilização nitrogenada, independentemente da oferta de forragem utilizada, elevou a produção de MS de forragem. Estes dados indicam que o suprimento de nitrogênio no solo normalmente não atende à demanda das gramíneas por este nutriente. O comportamento observado segue o mesmo padrão encontrado por Fagundes et al. (2005) e pode ser atribuído à grande influência do nitrogênio sobre os processos fisiológicos da planta.

Além disso, a maior oferta de forragem manteve a disponibilidade de MS mais elevada em todos os períodos avaliados. Essa observação é condizente com os dados de Barbosa et al. (2006), que encontraram resposta linear positiva da disponibilidade de matéria seca às ofertas de forragem praticadas

No primeiro período de avaliação, observou-se que, nas doses mais elevadas de nitrogênio, houve redução da disponibilidade de MS. O intervalo de 86 dias, entre a fertilização da pastagem e a primeira avaliação permitiu elevado acúmulo de MS e da altura do pasto, provavelmente reduzindo a vida das folhas localizadas nos estratos inferiores do pasto, pelo autossombreamento.

Os teores de nitrogênio sofreram pequena variação com as doses aplicadas ao sub-bosque. Na dose de $10 \%$, foi verificado comportamento quadrático $(\mathrm{P}<0,05)$ no primeiro período, e comportamento linear $(\mathrm{P}<0,05)$ nos demais períodos. Para oferta de $15 \%$ foi verificado comportamento linear $(\mathrm{P}<0,10)$ nos períodos 1 e 2 , não sendo detectado $(\mathrm{P}>0,10)$ efeito significativo no terceiro período.

Para a oferta de $10 \%$, observou-se aumento do teor de nitrogênio com a adição de doses crescentes de fertilizante nitrogenado. O mesmo efeito não pode ser observado para a oferta de $15 \%$. Neste caso, observou-se leve aumento no teor de nitrogênio na primeira avaliação, decrescendo na segunda e mantendo-se constante na terceira avaliação, à medida que se aumentaram as doses do adubo nitrogenado. Isso pode ser justificado pelo efeito de diluição causado pela elevação do rendimento de matéria seca observado com a aplicação do adubo, e pela maior disponibilidade de forragem utilizada neste tratamento. Para a oferta de $10 \%$, a renovação foliar é mais intensa, uma vez que a intensidade e frequência de pastejo passam a ser maiores com a maior pressão de pastejo. Segundo Almeida et al. (2000), ao aumentar a oferta de forragem, pode não haver efeito ou ocorrer pequena variação negativa nos teores de nitrogênio na planta.

Os conteúdos de nitrogênio no sub-bosque foram significativamente influenciados pela adubação nitrogenada, em ambas as ofertas de forragem. Na avaliação da oferta de 
Tabela 4 - Disponibilidade de matéria seca e composição do pasto nos períodos avaliados

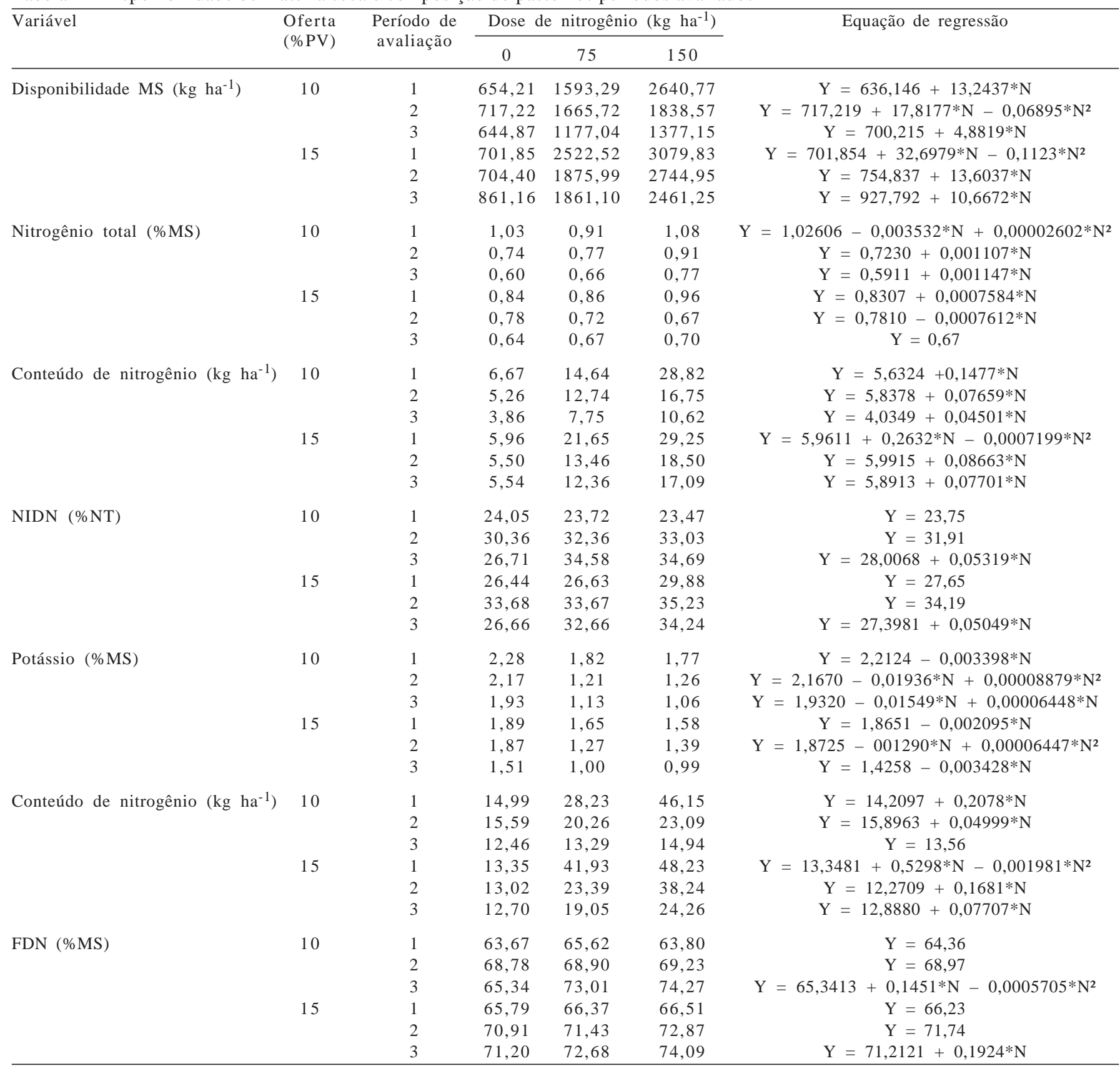

NIDN: nitrogênio insolúvel em detergente neutro; FDN: fibra em detergente neutro.

$10 \%$, verificou-se comportamento linear $(\mathrm{P}<0,01)$ em todos os períodos de avaliação. Para a oferta de $15 \%$, foram observados comportamento quadrático $(\mathrm{P}<0,05)$ no primeiro período e linear $(\mathrm{P}<0,01)$ nos demais períodos de avaliação.

Apesar do efeito diverso das ofertas de forragem no teor de nitrogênio da planta, os conteúdos desse nutriente na planta aumentaram em todos os tratamentos avaliados. À exceção do período 2, em que os conteúdos de nitrogênio nas ofertas 10 e $15 \%$ permaneceram próximos, nos demais períodos de avaliação, foi observado maior conteúdo de nitrogênio para oferta de 15\%. As doses crescentes de adubo nitrogenado elevaram a disponibilidade de MS do pasto e, consequentemente, o conteúdo de nitrogênio.

Na análise de variância, verificou-se efeito das doses de nitrogênio em ambas as ofertas de forragem nos teores deste elemento na planta. Para a oferta de $10 \%$, observaram-se efeito linear $(\mathrm{P}<0,01)$ no primeiro período e quadrático $(\mathrm{P}<0,01)$ nos períodos 2 e 3 . Avaliando o pasto submetido à oferta de $15 \%$, constatou-se comportamento quadrático $(\mathrm{P}<0,10)$ no primeiro e terceiro períodos e linear $(\mathrm{P}<0,05)$ no segundo período. 
O conteúdo de potássio foi influenciado pelas doses de nitrogênio aplicadas. Foi observado, para as ofertas de $10 \%$, comportamento linear nos períodos $1(\mathrm{P}<0,01)$ e 2 $(\mathrm{P}<0,10)$. No terceiro período de avaliação, não houve efeito $(\mathrm{P}>0,10)$ sobre esta variável. Para a oferta de $15 \%$, foi detectado efeito $(\mathrm{P}<0,01)$ das doses de nitrogênio sobre o conteúdo de potássio, sendo observados comportamentos quadrático no período 1 , e linear nos períodos 2 e 3.

A redução dos teores de potássio na planta com a aplicação de fertilizante nitrogenado é esperada, devido ao efeito de diluição que ocorre quando se eleva a produção de matéria seca de forragem. Entretanto, a queda nos teores de potássio não foi suficiente para prejudicar o conteúdo de potássio do sub-bosque. Esta variável aumentou à medida que se adicionou fertilizante nitrogenado, mantendo-se mais elevada nas condições propiciadas pela oferta de $15 \%$, em relação àquela de $10 \%$.

Não foi detectada $(\mathrm{P}>0,10)$, por meio da análise de variância, alteração nos teores de FDN da forragem disponível pela adubação nitrogenada nos dois primeiros períodos de avaliação para as duas ofertas de forragem. Entretanto, foi verificado efeito da adubação no terceiro período. Ao se avaliar estes efeitos nas parcelas com oferta de $10 \%$ de forragem, verificou-se efeito quadrático $(\mathrm{P}<0,05)$ das doses de nitrogênio sobre esta variável, enquanto, para a oferta de $15 \%$ de forragem, foi detectado efeito linear $(\mathrm{P}<0,10)$. Entretanto, a magnitude das variações é pequena e permite considerar que os teores de FDN neste trabalho não são capazes de restringir o desempenho animal, desde que não haja formação de complexos lignificados. Foram encontrados valores médios de 64,4; 69,0 e $70,9 \%$ para oferta de $10 \%$, e de 66,$2 ; 71,7$ e $72,7 \%$ para oferta de $15 \%$, nos períodos 1 , 2 e 3, respectivamente.

Mesma tendência foi observada para os teores de nitrogênio insolúvel em detergente neutro. Esta variável foi influenciada pela adubação nitrogenada, nas duas ofertas de forragem, apenas no terceiro corte. O comportamento observado foi linear $(\mathrm{P}<0,05)$ para ambas as ofertas. Nos cortes anteriores não foi verificada influência $(\mathrm{P}>0,10)$ da aplicação de nitrogênio sobre esta variável.

De maneira geral, foram observados maiores teores de NIDN para os sistemas mantidos com oferta de $15 \%$ nos dois primeiros períodos de avaliação. Observou-se maior resíduo de MS, composto por maior fração de colmos, conferindo maiores teores de NIDN à planta.

O ganho de peso aumentou $(\mathrm{P}<0,01)$ apenas no primeiro período de avaliação à medida que se elevaram as doses de fertilizante nitrogenado (Tabela 5). Nos demais avaliações, o ganho de peso não foi influenciado $(\mathrm{P}>0,10)$ pelas doses de nitrogênio.

$\mathrm{O}$ aumento do ganho de peso individual do primeiro período em função das doses de nitrogênio pode estar relacionado à resposta inicial da forrageira à adubação, elevando sua qualidade nutricional e produção de MS, permitindo aos animais a seleção de tecidos de maior valor nutritivo. Evidência disso é o fato da forrageira disponível não apresentar teor de PB superior a 7\%, valor mínimo recomendado na literatura para adequada fermentação ruminal (NRC, 1984). Ainda assim, os animais, pelo processo de seleção, foram capazes de consumir uma dieta quali e quantitativamente adequada às suas exigências de mantença e produção. Gomide et al. (2001) ressaltam que amostras de lâmina foliar apresentam teores de PB superiores à planta inteira. Dessa forma, ao preferir estes tecidos no processo de seleção da dieta, os animais estão ingerindo alimento maior teor de PB do que os valores de planta inteira avaliados neste trabalho.

A variação na oferta de forragem não influenciou os ganhos médios individuais nos dois últimos períodos de avaliação, evidenciando que as ofertas de 10 e $15 \%$ não afetaram o comportamento ingestivo dos animais. Alguns resultados encontrados na literatura, como os de Barbosa et al. (2006), demonstram que a produção animal pode ser elevada à medida que se elevam as ofertas de forragem, devido à maior disponibilidade de MS aos animais. Posteriormente, ao elevar ainda mais a oferta, há a redução do ganho individual pela queda da qualidade da forrageira que tende a acumular maior proporção de tecidos

Tabela 5 - Ganho de peso médio diário (GMD) de novilhos em sistema silvipastoril com duas ofertas de forragem e adubado com fertilizante nitrogenado

\begin{tabular}{|c|c|c|c|c|c|c|}
\hline \multirow[t]{2}{*}{ Variável } & \multirow{2}{*}{$\begin{array}{l}\text { Oferta } \\
(\% \mathrm{PV})\end{array}$} & \multirow{2}{*}{$\begin{array}{l}\text { Período de } \\
\text { avaliação }\end{array}$} & \multicolumn{3}{|c|}{ Dose de nitrogênio $\left(\mathrm{kg} \mathrm{ha}^{-1}\right)$} & \multirow[t]{2}{*}{ Equação de regressão } \\
\hline & & & 0 & 75 & 150 & \\
\hline \multirow[t]{4}{*}{ Ganho médio diário $\left(\mathrm{kg} \mathrm{dia}^{-1}\right)$} & 10 & 1 & 0,392 & 0,667 & 0,892 & $\mathrm{Y}=0,40+0,003333 * \mathrm{~N}$ \\
\hline & & 3 & 0,542 & 0,517 & 0,442 & $\mathrm{Y}=0,50$ \\
\hline & 15 & 1 & 0,483 & 0,817 & 0,725 & $Y=0,4833+0,007278 * N-0,00003778 * N^{2}$ \\
\hline & & 2 & 0,492 & 0,500 & 0,525 & $\mathrm{Y}=0,51$ \\
\hline
\end{tabular}


lignificados e senescentes. Entretanto, no presente trabalho, as ofertas de forragem estudadas podem ser consideradas adequadas, pois não limitaram o consumo do animal, e nem mesmo houve queda da qualidade da forragem. De maneira semelhante, Gomide et al. (2001) também não encontraram vantagens do incremento da oferta de forragem, de 4 para 8\% do PV sobre o desempenho de vacas leiteiras em pastagem de Brachiaria decumbens.

Os ganhos observados podem ser considerados moderados para animais pastejando Brachiaria brizantha em lotação contínua. Trabalhos recentes realizados a pleno sol mostram ganhos variando em torno de $0,600 \mathrm{~kg} / \mathrm{animal} / \mathrm{dia}$ em lotação contínua, o que evidencia o potencial de utilização de sistemas silvipastoris na produção de bovinos de corte.

Os valores de ganho médio individual não prejudicaram o ganho por unidade de área. Foram observados ganhos crescentes à medida que foram adicionadas doses de fertilizante nitrogenado. Devido ao aumento da produção de MS, a capacidade de suporte dos pastos adubados foi elevada, refletida pelas maiores taxas de lotação utilizadas. Assim, foi possível produzir maior quantidade de peso vivo por unidade de área (Tabelas 6 e 7).

A maior disponibilidade de forragem reduziu o ganho de peso acumulado no final do período experimental e o ganho por unidade de área, na dose de $150 \mathrm{~kg} \mathrm{ha}^{-1}$ de fertilizante nitrogenado. A intensificação do pastejo nesta dose mais elevada de nitrogênio foi importante para elevar a produção por unidade de área. Ao longo dos três períodos de pastejo, foi observado maior teor de nitrogênio nas plantas submetidas a $10 \%$ de oferta e adubação de $150 \mathrm{~kg}$ $\mathrm{ha}^{-1}$ de N. Esse efeito pode ter refletido no ganho individual acumulado, e associado à alta disponibilidade de MS, contribuiu para o maior ganho por unidade de área observado.

Tabela 6 - Taxas de lotação observadas durante o período experimental

\begin{tabular}{|c|c|c|c|c|}
\hline \multirow[t]{2}{*}{ Dose de nitrogênio $\left(\mathrm{kg} \mathrm{ha}^{-1}\right)$} & \multirow[t]{2}{*}{ Oferta de forragem (\%PV) } & \multicolumn{3}{|c|}{ Taxa de lotação $\left(\mathrm{UA} \mathrm{ha}{ }^{-1}\right)$} \\
\hline & & Período 1 & Período 2 & Período 3 \\
\hline 0 & 10 & 0,55 & 0,68 & 0,52 \\
\hline \multirow[t]{2}{*}{75} & 10 & 1,17 & 1,40 & 0,96 \\
\hline & 15 & 1,29 & 1,04 & 1,11 \\
\hline
\end{tabular}

Tabela 7 - Ganho de peso acumulado dos três períodos e ganho total por hectare (G/ha) de novilhos em sistema silvipastoril

\begin{tabular}{cccc}
\hline Dose de nitrogênio $\left(\mathrm{kg} \mathrm{ha}^{-1}\right)$ & Oferta de forragem $(\% \mathrm{PV})$ & ${\text { Ganho de peso acumulado }\left(\mathrm{kg} \text { animal }{ }^{-1}\right)}_{\text {Ganho total }\left(\mathrm{kg} \mathrm{ha}^{-1}\right)}$ \\
\hline 0 & 10 & 43,5 & 57,83 \\
& 15 & 44,5 & 50,83 \\
75 & 10 & 49,5 & 132,33 \\
& 15 & 50,0 & 144,00 \\
150 & 10 & 57,5 & 197,72 \\
& 15 & 52,3 & 175,50 \\
\hline
\end{tabular}

\section{Conclusões}

A aplicação de fertilizante nitrogenado aumenta a disponibilidade de matéria seca do sub-bosque de um sistema silvipastoril, elevando sua capacidade de suporte e o ganho de peso animal por unidade de área. A oferta de forragem de $15 \%$ é mais adequada quando se utilizam menores doses de nitrogênio. Para doses mais elevadas, a intensificação da utilização, representada pela oferta de forragem de $10 \%$, é mais elevada, com maiores ganhos por unidade de área.

\section{Referências}

ALMEIDA, E.X.; MARASCHIN, G.E.; HARTHMANN, O.E.L. et al. Oferta de forragem de capim-elefante anão "Mott" e o rendimento animal. Revista Brasileira de Zootecnia, v.29, n.5, p.1288-1295, 2000.

BARBOSA, M.A.A.F.; NASCIMENTO JÚNIOR, D.; CECATO, U. Dinâmica da pastagem e desempenho de novilhos em pastagem de capim-tanzânia sob diferentes ofertas de forragem. Revista Brasileira de Zootecnia, v.35, n.4, p.1594-1600, 2006. (supl.)

FAGUNDES, J.L.; FONSECA, D.M.; GOMIDE, J.A. et al. Acúmulo de forragem em pastos de Brachiaria decumbens adubados com nitrogênio. Pesquisa Agropecuária Brasileira, v.40, n.4, p.397-403, 2005. 
GARCIA, R.; COUTO, L. Sistemas silvipastoris: tecnologia emergente de sustentabilidade. In: SIMPÓSIO INTERNACIONAL SOBRE PRODUÇÃO ANIMAL EM PASTEJO, 1997, Viçosa, MG. Anais... Viçosa, MG: Departamento de Zootecnia/Universidade Federal de Viçosa, 1997. p.447-471.

GOMIDE, J.A.; GOMIDE, C.A.M. Utilização e manejo de pastagens. In: REUNIÃO ANUAL DA SOCIEDADE BRASILEIRA DE ZootecniA, 38., 2001, Piracicaba. Anais... Piracicaba: Sociedade Brasileira de Zootecnia, [2001] (CD-ROM).

GOMIDE, J.A.; WENDLING, I.J.; BRAS, S.P. et al. Consumo e produção de leite de vacas mestiças em pastagem de Brachiaria decumbens manejada sob duas ofertas diárias de forragem. Revista Brasileira de Zootecnia, v.30, n.4, p.1194-1199, 2001.

LICITRA, G.; HERNANDEZ, T.M.; VAN SOEST, P.J. Standardization of procedures for nitrogen fractionary of ruminant feeds. Animal Feeding Science and Technology, v.57, n.4, p.347-358, 1996.

MOTT, G.O.; LUCAS, H.L. The design, conduct and interpretation of grazing trials on cultivated and improved pastures. In: INTERNATIONAL GRASSLAND CONGRESS, 6., 1952, Pennsylvania. Proceedings... Pennsylvania, 1952. p.1380.

NAIR, P.K.R. An introduction to agroforestry. London: Kluwer Academic Publishers, 1993. 499p.

NATIONAL RESEARCH COUNCIL - NRC. Nutrient requirements of beef cattle. Washington, D.C.: National Academy of Science, 1984. 90p.

PAYNE, W.J.S. A review of the possibilities for integrating cattle and tree crop production systems in the tropics. Forest ecology and management. v.13, p.1-36, 1985.

SILVA, D.J.; QUEIROZ, A.C. Análise de alimentos: métodos químicos e biológicos. Viçosa, MG: Editora UFV, 2002. 235p. 